\title{
Evaluating the Effects of Commercialized Security on National Security in Nairobi County, Kenya
}

\author{
Gerald Peter Mutonyi ${ }^{1}$, Merecia Ann Sirera ${ }^{1}$ \\ ${ }^{1}$ Kenyatta University \\ P. 0. Box 43844-00100, Nairobi, Kenya
}

DOI: $10.22178 /$ pos.58-8

JEL Classification: K40

Received 26.03.2020

Accepted 28.05.2020

Published online 31.05.2020

Corresponding Author: Gerald Peter Mutonyi

mutonyig@gmail.com

(c) 2020 The Authors. This

article is licensed under a

Creative Commons

Attribution 4.0 License

(c) (i)
Abstract. The growth and expansion of commercialized security markets are as a result of deficiencies in the ability of nations to effectively deliver security-related services. Therefore, a range of players is explicitly looked upon to supplement the supply of security services. Perhaps, the most important of these players are the commercial security firms, which have developed and grown expansively. These firms provide some aspect of security/policing services to their fee-paying consumers aimed at protecting the people and their physical assets, as opposed to public security which is a public good. The commercialized security industry has grown and expanded in Nairobi, Kenya, and offers a range of security services. Despite this development, few studies have examined the effects of these services on national security in Nairobi, Kenya. Using the Security Governance theory and Network Analysis theory, this study sought to understand the subject matter.

The study took on a cross-sectional survey design and was carried out in Nairobi with the adult residents as the target population. A multistage sampling technique was employed to obtain the wards to be studied, whereas those who purchase or manage commercial security services for their organizations and management of the commercial security firms were purposively sampled, the general public and the security guards were systematically sampled. Questionnaires, scheduled interviews, and structured observation were used to collect data. The Statistical Package for Social Sciences (SPSS version 25, 2017) was used in data management and analysis. In the analysis, descriptive statistics used included percentages and frequency distribution tables. These descriptive statistics were used to summarize variables into thematic areas and to convey the characteristics of key variables. Inferential statistics used was Multiple Regression analysis to establish relationships, provide predictions, and in concluding.

The results demonstrated that the study identified five effects with each having a unique variance on national security: Visible presence that discourages criminal activities $(B=.372, \beta=.383, P=.001)$, detection of criminal and harmful activities by the electronic devices $(B=.250, \beta=.257, P=.001)$, intervention in stopping crime and harm $(B=.213, \beta=.194, P=.001)$, intelligence on criminal activities through surveillance $(B=.176, \beta=.159, P=.001)$ and creating a culture of security and crime awareness $(B=.086, \beta=.076, P=.024)$. Together, both were significant predictors of national security $F(5,368)=111.42, p<.001, R^{2}=.231$.

The study concluded that the effects of commercialized security on national security bring to fore the huge responsibility the industry is endowed with. Consequently, there should be favorable mechanisms in the country that can oversee the continuous development of the industry. The favorable mechanisms can only be realized through the consultation of the stakeholders: the commercial security industry, the citizens, and the state. Thus the study recommended that the Private Security Regulation Authority needs to start implementing some of the requirements that are in the PSRA No. 13 of 2016, which are meant to streamline the industry in terms of the training of the security guards, remunerations of the security guards, minimum requirements for recruitment and working environments. This is so that the country and citizens can benefit from the basis of which the authority 
was formed. It is expected that the findings of this research will provide data that can be used to inform policy and practice amongst commercial security providers to increase their impact on national security in Kenya. The data can also stimulate the academic community towards more research in the field.

Keywords: Commercial Security; Commercial Security Services; Security; National Security.

\section{INTRODUCTION}

The modern norm of national security dates back as far as the seventeenth century when Hobbes introduced the social contract. Man has a natural desire for self-protection and self-preservation, and entered into a contract the absolute authority or the sovereign who was to be obeyed in all but the sovereign had the moral obligations to protect and preserve the people's lives and property [32]. This was based on his theory of social contract where the citizens gave up their natural right to use force, and in return, to be protected by the state [27]. The objective of this contract was to outlaw violence among people and contain chaotic conflict. Granting the state, the monopoly to use violence within its borders, and to enforce these objectives is what is described as national security. The provision of security as the most vital obligation of the state was also influenced by the views of Max Weber. The 'Weberian State' enjoyed the monopoly of the legitimate use of physical violence [45]. Accordingly, the state is presumed to be responsible for the provision of internal security and defense from external threats.

However, the state establishments are limited in warranting fairness in the circulation of security to all the citizens and visitors to society [8]. The state consequently, focuses the delivery of security to its vital installations and some citizens, while the other citizens and their property are placed in a one fit all suit despite, their varied security needs. The different security needs by the citizen's places many demands that are beyond the capability of the state, making it challenging for equal distribution of security service [8]. Some studies have correlated the growth and expansion of commercialized security markets with deficiencies in the ability of nations to effectively deliver security-related services $[1 ; 10]$. Therefore, a range of actors is explicitly looked upon to supplement the supply of security services [60]. Perhaps, the most important of these actors in the commercial security industry (CSI), which has grown expansively in both developed and developing countries.
Commercial Security comprises enterprises that provide some aspect of security/policing services with a profit motive [53]. Commercial security is described as fee-paying services aimed at protecting persons and physical assets [8; 60]. It was therefore important to evaluate the effects of commercialized security on national security.

From a historical perspective, commercialized security played a major role in the history of the USA, and its presence has expanded since the 19th century. The growth of the commercial/industrialization sector, the great westward expansion of America in the 1840s and 1850s, and the U.S. railroad systems were the major factors in the 19th century which contributed to the expansion of commercialized security [40]. Trains often carried large stashes of cash and precious minerals passing through a sparsely populated landscape, which provided bandits with numerous isolated areas perfect for robbing them [64]. This prompted the railroad owners to fight back to protect their investments by having armed commercial guards, and even customized fortified boxcars which are the predecessor of the current armored cash and valuables in transit vehicles [64]. Similarly, there was the transport of cargo on both sides of the Missouri River, which led Henry Wells and William Fargo in 1850 to form Wells and Fargo [17]. In essence, it is the need for individuals to protect their valued property that provided the impetus for investing in commercialized security [17]. Since then, the CSIs in the USA has been involved in a wide range of services, including manned guarding, alarms, cash and valuables in transit, correctional facilities management, systems integration and management, security consulting, pre-employment screening, and information security [54]. Each of the services or accumulatively affects the security of the citizens and their property. This, therefore, provided the impetus to undertake the study.

The precise dimensions of the size and growth of the Australia security industry followed an international trend of substantial growth in security services in the last three decades of the 20th cen- 
tury because of two main factors. First, was the market demand, partly in response to steep rises in crime from the 1960s, and the continuing high levels of crime [48]. However, the information on the effects of commercialized security on crime control in Australia is limited. Secondly, was the shift in consciousness away from the reliance on police providing security to the society to a mentality of self-protection [48]. Self-protection is a concept of human security in which all people are expected to take part in the responsibility of their security. The commercial security firm's (CSFs) personnel in Australia are involved in crowd control, patrolling and guarding facilities, the security of courts, risk management, gathering of evidence, and case investigation [53]. However, inquiries into the commercial security industry conducted by the Australian Crime Commission and the New South Wales Independent Commission against corruption identified negative effects. These include the potential for criminal activity and the infiltration by organized criminal gangs [47]. This raises the question as to the effect of commercialized security on the national security of Australia.

In Africa, the CSI is in most countries including South Africa, Nigeria, Tanzania, and Kenya. The expansion of CSI in South Africa can be attributed to the escalation of crime [5]. The commercial security personnel now outnumber public policy in South Africa [14]. In Nigeria, the commercialized security industry has been able, to some extent, supplement the activities of the police in the management of security despite the challenges confronting them [3; 22]. In Tanzania, the total number of commercial security guards is close to 1.2 million, as compared to less than 1 million police officers [35]. The Tanzanian police force, therefore, collaborates with the CSI to offer security services to government buildings and institutions such as forex bureaus [35]. Commercialized security in Africa appears to be used to enhance national security, but there is a dearth of knowledge on its effects on national security.

In Kenya, the rise in crime and the growth of the commercialized security industry is pegged on the decline of state capacity, which began in the late 1980s and continued to the 1990s [2]. This was a period of declining economic prosperity in Kenya and many African countries, as state expenditure and investment reduced drastically to conform to Washington Consensus. The Washington Consensus was based on envisaged supportive policies to enable the developing coun- tries to revive their economies and their ability to service their debts. A range of policies, collectively known as structural adjustment policies, was developed [50]. These policies advocated for liberalization of inward foreign direct investment, reduction in state investment via privatization of state enterprises, and deregulation: abolition of regulations that impede market entry

Drawing on the views of Williamson and Robertson et al, it was observed that a conditionality clause for development loans ensured that the developing countries adopt neo-liberal policies [52]. As a result, the state security agencies were under-funded, losing the ability to deliver services, including the provision of security. The reduced state power also implied that the state could not effectively regulate the commercial security industry. This could be suggestive that as independent institutions, they could offer service depending on the needs of individual customers, which may not be necessarily in line with national security. This may be indicative of the different security interests between the nation and individuals, suggesting possible different outcomes from the perceived state security. Therefore, an empirical study to determine the effect of commercialized security on national security was necessary.

Accordingly, the proponents of neoliberalism may be opposed to redistributive policies of social welfare: upholding social contract between labor and capital, because neoliberal philosophy is pro-business, interested in profit-making [37]. This, therefore, raises the question as to the effect of commercialized security on national security, which is premised on the social contract. However, despite the philosophical differences that provide the models of security, there is limited empirical knowledge on the effects of commercialized security on national security.

A study on the factors affecting the performance of commercial security firms in Nairobi County showed that security conditions in the country would greatly improve with a well-regulated CSI and appeared to allude to the importance of a well-regulated industry [24]. But it fell short in providing a holistic explanation of the effects of commercialized security on national security.

The study examining commercialized security services and crime control in Nairobi County pointed out that citizens opt for CSFs for their security needs [26]. The CSFs are seen to be able to tailor their service to each particular customer, 
unlike the public security agencies who serve the community collectively. The extent of the effects to which these tailored security services on national security are left unaddressed in the study. Also, the study revealed that the government needs to regulate the CSI roles as security providers to achieve oversight and control over them. This could imply that some of the services offered by CSI may not be aligned with national security, thereby creating a need to study the effects of commercialized security on national security.

Further, a study on how the availability of commercial security services assists in crime control in Nairobi County identified five categories of crime control services provided: alarm response, mobile patrols, residential security, security surveillance in marked security vehicles at strategic points, and regulating public access control to buildings [31]. Despite these security services, insecurity is still experienced in Nairobi. A Crime and Safety report by the US Department of State's Bureau of Diplomatic Security Kenya in 2017, identified home invasions, burglaries, armed carjackings, kidnappings, and street crimes, as the most common crime in Kenya's major cities, and in particular, Nairobi [43]. The UN, whose agencies have a large presence in Nairobi, reported that the number of burglaries in Nairobi doubled to 300 from the last quarter of 2013 to the first quarter of 2014 [25]. Also, the national police service annual crime report reported that the number of crimes in Nairobi as having increased by $4.6 \%$ between 2014 to 2015 , and by $6.2 \%$ between 2015 and 2016 [57]. This is a 10.8\% increase in crime in 2 years (between 2014 - 2016) and this is despite the heavy presence of commercial security. Therefore, the problem that provides the impetus for this study is that although commercialized security has expanded in Kenya, and continues to offer customized security services to its customers, there is limited empirical information on its effects on national security. This study, therefore, sought to examine the effects of commercialized security on national security in Nairobi City County, Kenya.

\section{Literature Review}

The old-fashioned understanding of national security denoted that a state, under usual circumstances, was to identify external threats and develop moderating strategies to be able to withstand such dangers [46]. The USA national secu- rity is pegged on the abilities of its national institutions to inhibit enemies from using force to harm its citizens or its national interests and the confidence of the citizens in these capabilities [51]. The Russian Federation National Security involves the protection of state and the Russians citizens, and the need to progress the living standards of Russians and also increasing its economic growth [42]. Accordingly, the Japan national security is to defend its territorial integrity, to maintain its sovereignty and independence, to ensure the safety of life, person, and properties of its nationals, and to ensure its survival while maintaining its peace and security grounded on freedom and democracy and preserving its rich culture and tradition [39]. South African national security is pursued chiefly through the realization of the political, economic, social, and cultural rights and needs of the citizens, and efforts to promote and maintain regional security [30]. The Constitution of the Republic of Kenya, Chapter 14, section 238 directs that its national security shall be the territorial integrity and sovereignty, its people, their rights, freedoms, property, peace, stability and prosperity, and other national interests [56]. However, increased pressure on the national security agencies resulted in the commercialization of some of state security agencies' functions, with the commercial security industry (CSI) filling the gaps created as the state security agencies get overstretched. The progression of societies and the intricacy of urban setting increased calls of security, leading to alternative approaches of security including the commercial security industry. Therefore, national security alone barely was adequate to provide security in ways consistent with the progressive objectives of contemporary society. Despite these diverse orientations of various nations, the cumulative effects of the commercialized security on national security remain unclear.

Many countries are often outsourcing functions that had always been a duty of their military and police from the commercial security firms, partly due to the reduction of the public service sector downsizing, but also due to the evolved and changed warfare [13]. This has been to reduce the burden of security needs in a state and to satisfy its demands on life and property [27]. Therefore, the effects of commercialized security have become pronounced in developed countries, and developing countries. Generally, the large and expanding commercial security industry is endowed with notably large and often complex re- 
sources to stop criminals and harm and thus preventing damages and losses [11]. The practices of the commercial security industry are prone to produce security associated effects, which can go beyond the direct circle of their paying consumers, and either contribute towards or undermine an overall feeling of the public security.

For example, in Brazil, France, the United States, Lesotho, and Canada, commercial security firms are in charge of the prisons' administration [13]. This new model of provision of security makes it possible for governments and its establishments, to be efficient on their core functions of securing the borders and providing reactive security need as surplus responsibilities have been transferred to the commercial security industry. It was, therefore, important to address the effects of commercialized security nation's security agencies are concentrating their core functions.

A 'Persons of Versatility' by Wilkie in Hong Kong, examined two case studies of separate estates by studying the security practitioners and consumers, observing work practices, and analysis of documentaries. The study found that in residential estates, commercial security agents were enforcing orders of property owners and maintenance of some quality of life of residents [63]. Commercial security also provided residents with customized services focusing on neighborhood security and harmony [63]. In China, most of the activities for commercial security firms are domestic and encompassing a range of protection services from bodyguarding to facility security [15]. Despite these ambiguous effects of quality of life of residents, and customized service focusing on neighborhood security and harmony, the specific effects of the commercialized security on national security remains unclear.

Gerasimoski in his study 'Obstacles to Reconciliation and Stability in the Namibian State and Society' concluded that commercialized security is mostly practiced as preventive in its orientation [18]. But the effects of the preventive orientation were not highlighted. The responsibilities of the commercial security industry also include monitoring of closed-circuit televisions and alarms, loading automated teller machines (ATMs), and transportation of cash and valuables [20]. The surveillance strategies carried out by commercial manned security guards are much more than a policing approach. Instead, they are a central factor in wider strategies of security management that are important to the success of managing public areas [36]. Commercial security offers a range of services. The effects of these services on the overall national security is a concern of this study.

In their study on commercial security firms and crime control in Nigeria, Inyang and Ubong explored the role of commercial security firms and the control of insecurity in the Akwa Ibom State of Nigeria. The study revealed that the commercial security sector in Nigeria has been compromised by people not registered and licensed, hence constituting a higher security risk in the country [22]. The implication of the study is the view created that the commercial security industry can be a cause of insecurity in the community. Based on the findings, the risk profile of the CSFs in Nigeria was raised, and therefore, the cumulative effect of commercialized security on national security remains unclear. Similarly, Prenzler and Sarre in their book 'Regulation. In The Handbook of Security Management' observed that, despite its relative anonymity, commercial security has the potential to harm innocent members of society, hence necessitating a need for a robust legal framework for regulation to avoid violence, harassment, trespassing and false arrests [48]. This equivocal view of commercialized security provided the impetus to conduct this study to verify the effects of commercial security on national security in Nairobi, Kenya.

The study by Litavski 'Challenges of Private Security Sector in the New Century' states that, due to the use of force by the commercial security agencies, they contribute to an increase or a decrease of citizens' security and therefore, requires a detailed and precise legal regulation that would enable them to observe standards of human rights [29]. This study, therefore, embarked to find out the effects of these players on national security when they are increasing or decreasing the security of citizens.

In general, commercialized security activities run parallel and supplement state security agencies' operations [10]. Similarly, the CSI should not be ignored easily as it has a reputation in the prevention of crime [20]. The industry is involved in a wide range of activities including guarding, alarm monitoring, armored transport, systems integration and management, correctional facilities management, security consultancy, and preemployment screening [54]. However, as revealed by the study in Nigeria, commercial security can pose insecurity for national security. 
There is a need to understand more about what commercial security personnel is doing, the rationale for their activities, and whether these rationales are supported by empirical data. Therefore, the assumption that the effects of commercial security are always positive on national security may have challenges.

Mutonyi and Sirera in their study on commercial security's effect on security showed that there was an accepted positive effect on the security of Kenyans in private functions and venues where commercial security was present [38]. They also pointed out grey areas that needed legal backing so that efficiency would be achieved [38]. But they failed short to demonstrate the effects of commercial security. This study, therefore, embarks to show the effects of commercial security on national security in Nairobi, Kenya.

\section{Theoretical Framework}

This study was guided by two theories: Security Governance theory and Network Analysis theory. The two are taken as appropriate theoretical frameworks for analyzing and interpreting the commercialized security phenomenon and national security, not only in Kenya but worldwide as well.

Security Governance Theory. This research was guided by the Security Governance theory. The researcher drew a relation to how they can be used for the examination of commercialized security services on national security. The concept of security governance has its proponents like Arquilla and Ronfeldt and Markusen [4; 33]. As a theoretical concept, security governance is founded on three premises contending on the nature of modern international security relations. But this study will peg itself on the second premise. The second, premise is that the multiplicity and complexity nature of modern security threats have challenged the ability of sovereign nation-states to ensure the security of their citizens [4]. Since the new dangers can transgress territorial boundaries, states are increasingly required to collaborate and cooperate, and also to draw on non-state actors such as international organizations, NGOs and commercial organizations to combat them. Some of these commercial organizations are the commercialized security industry. This industry provides services, which together with the state security agencies provide personal security to their customers, and also detect the illegal and activities that may affect the nation as a whole.

The theory proposes that if states are no longer wholly concerned with dangers from other states, but rather concerned with those emanating from non-state actors, then states need to freely work jointly with other states and nonstate actors. As part of the non-state actors, the commercialized security industry works feely with the state to confront dangers and harms like the prevention of terrorism, mugging of the citizens, and trafficking in illegal items like guns and drugs. While the emergence of security governance might contribute to explaining the proliferation of networks and alliances as a mode of coordination, and some of its implications, as a theoretical model it fails to illustrate how coordination proceeds within particular networks and alliances arrangements. Network analysis has proposed some answers to this question.

Network Analysis Theory. The basic premise of network analysis is that, in addition to the character, beliefs, and interests of actors, the relations among a set of actors: their preferences, policies or resource exchanges, have a major impact on how they interact and on the outcomes of these interactions [9]. In particular, in networks involving different types of actors, for instance, state security agencies and commercial security industry, coordination is frequently complicated by differences in values and interests and may, therefore, require more direct negotiation [34]. For example, the value of state security is in the common good, while for commercialized security the value is in the customer who pays for the services. This could create challenges of coordination as the CSFs would sometimes want to be specific and provide disintegrated security in an area (for instance, focus only on the premises that have subscribed for their services). Decentralized networks, on the other hand, allow for the making and implementation of security policies that enable localized action and autonomy [4]. Since security varies from one region to another, how the state security agencies will interact with the commercialized security players will vary too from one region to another. The outcomes of these interactions will also vary, and this forms the basis of how the relations are formed, either formal or informal relations, stable or unstable. 


\section{RESEARCH METHODOLOGY}

A cross-sectional design was adopted for the study; as different respondents were studied at the same time. It gives a stronger likelihood of participation. It also helped to gather objective information that was used for generalization to a larger population. The design also fits diverse experiences into predetermined response categories.

The research was carried out in Nairobi County, where the capital of Kenya sits and most CPFs have their headquarters. Stratified sampling was used to cluster the target population into homogenous groups as:

Consumers of the commercialized security services:

1. Those who buy or manage commercial security services for their organizations. These are mostly security managers and officers, and

2. The general public.

And the providers of commercialized security services:

1. Those working as operations/heads of security.

2. Those who work as static security guards and mobile security guards.

The study used Krejcie and Morgan table to arrive at the figure to be sampled (Appendix 1). The population of the study fell under N 100,000, and therefore, the sample size was 400 . The respondents were clustered as: consumers ( $\mathrm{n}=$ $200)$, and Providers $(n=200)$.

The consumer respondents of commercialized security services were divided as, 50 as security managers/officers, and 150 from the general public who have experienced commercial security services in functions or venues. Also, the providers of commercialized security services were divided as, 50 as operations/heads of security, and 150 workings as static security guards and mobile security guards.

The research targeted 114 commercial security firms in Kenya. There are 76 listed security firms at the Protective Security Industry Association, and 38 listed security firms at the Kenya Security Industry Association, in Kenya [28; 49]. The researcher used multistage sampling to get the sample size and to identify the respondents.
The study used structured questionnaires (completed by the guards of the CSFs, general public), and one-on-one interviews with open-ended questionnaires (with the top management members from both CSFs and the consumer organizations/facilities), and structured observation (of procedures and daily workings of security guards). The researcher delivered the questionnaires at the security firm's offices and picked up within three days. Follow-up calls were made to ensure success in filling in the questionnaires. Out of 400 questionnaires that had been administered to the interviewees, 374 were declared valid as they were not having any errors.

The data collected were analyzed using the Statistical Package for Social Sciences software (SPSS version 25, 2017). The analyzed data was then summarized using percentages, ratios, frequencies, and measures of central tendency. The percentages and ratios were important for comparing similarities and disparities at different levels. Multiple regression was done where further statistical analysis was required. There was an ethical consideration where the researcher informed all participants of their voluntary participation and confidentiality, and relevant authorization from the government agencies.

\section{RESULTS AND DISCUSSION}

This section present analyzes and interprets data related to objective two. Studies have shown that the commercial security industry is involved in activities that provide their customers with a customized service style of policing and encompassing a range of protection services from bodyguarding to facility security [15]. These activities have been credited to have several effects that could moderate national security by detecting, deterring, delaying, and reporting insecurity. They also affect to harm innocent members of society through violence, harassment, trespassing, and false arrests [48]. Therefore, it was important to examine these effects of commercial security on national security.

Respondents were asked to appraise the effects of commercialized security on national security by placing a mark next to the relevant option provided. The results are displayed in Figure 1 below.

A visible presence that discourages criminal activities was the most mentioned by 374 respondents which were $100 \%$. The detection of crimi- 
nal activities by electronic devices was mentioned by 368 respondents, which is $98.4 \%$ and came in second. Intelligence on criminals' activities through surveillance was third with mention by 355 respondents (94.9\%). Intervening in stopping crime was the fourth most identified effect of commercialized security on national se- curity with $326(87.2 \%)$ respondents. A reliable source of information was mentioned by 257 $(68.7 \%)$ respondents and was fifth. Lastly was creating a culture of security and crime awareness that was identified by 121 (32.4\%) of the respondents. These are discussed in the subsections below.

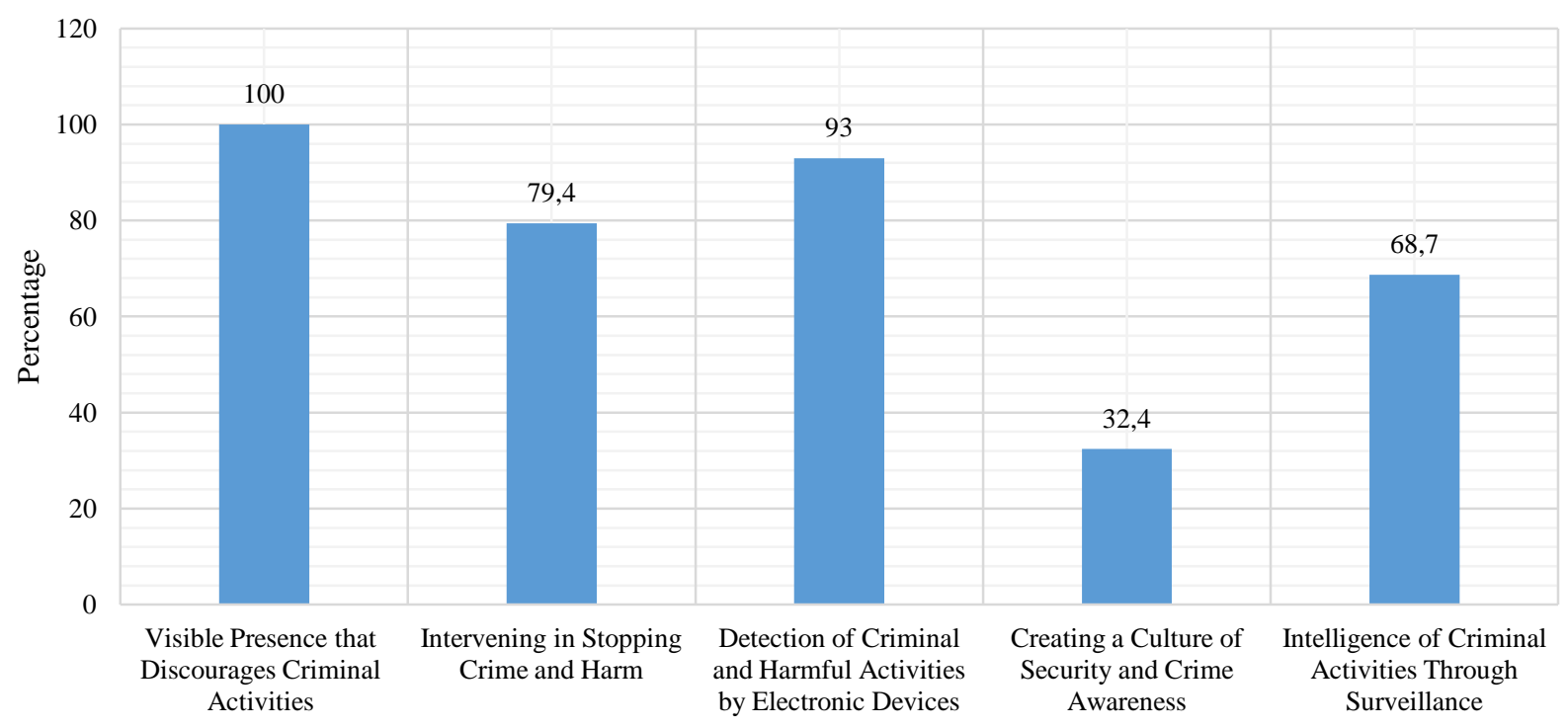

Figure 1 - Evaluated effects of commercialized security on national security

\section{Visible Presence that Discourages Criminal Activities}

The visible presence of commercial security measures that discourages criminal activities in public places was the most identified effect of commercialized security on national security with all the $374(100 \%)$ respondents acknowledging it helped deter or reduce criminality thus enhancing security. This is an indication that in the presence of guards, the citizens feel and experience security and safety from harm, losses, and destruction. A respondent explained...

"We can see the security guards are all over. So what can go wrong? We are feeling safe just with the knowledge that they are there".

The visible presence of security guards is so conspicuous. In the words of another respondent...

"You cannot miss seeing the security guards. They are easily identified by their uniform. It is reassuring on our safety when we see them".

In private residences and events, the presence of commercial security personnel is acknowledged. One participant had this to say...

"I stay in a gated community with hundreds of houses. Apart from the visible presence of the secu- rity guards at the main gate and in the courts' gate, they also patrol. It is very reassuring when you meet them and exchange greetings".

It can be deduced that the visible presence of the uniformed security guards gives a feeling of protection to the citizens. The very visible presence of commercial security services discourages criminal activities. Similarly, it had been argued that the plain visibility of commercial security mostly prevents crime commission [18].

The visible presence of the commercial security personnel as they get along with their patrols seems to be noticeable and cherished. Moving from one point to another not only makes the security guards alert, but it also makes it possible for them to curtail crimes that might be about to take place or that are taking place. The subscribers of the service are given a sense of peace knowing that there is an increased risk to wouldbe offenders. This is in line with what was, who stated that patrols in a British city were made a high priority to discourage crime on the public streets [41]. Similarly, it had been observed that there is an accepted positive effect on security in private functions and venues where commercial security is present [38]. Therefore, opportunities for crime are reduced when commercial security personnel is increasingly patrolling. 
Reassurance as depicted in the quote suggests a feeling of security that resonates with definitions of human security that stresses the need for freedom from fear and freedom from want. Accordingly, the security of individuals infers to the security of a nation [61]. Accordingly, in the new broader concept of security, individuals are at the center, and therefore the fact that individuals perceive themselves to be secure due to the visibility of the commercial security guards, it suggests the positive effects of commercial security. Subjective perception of security is likely to encourage individuals to engage in different economic activities, which feeds in another aspect of broader security namely economic security. Wolfers is cited as arguing that subjective safety has common ground with the concepts of 'risk perception', which can influence the decision making of people to engage in various nationbuilding activities [62]. Manned guards participate in key roles in the prevention of crime through their perceived status [6]. Also, the visible presence of commercial security personnel helped in the maintenance of order, suppression of gang violence, and enforcing security [59]. Furthermore, observations from the field (Appendix II) indicated that most of the commercial security personnel were kitted well to make them more visible (Figure 2).

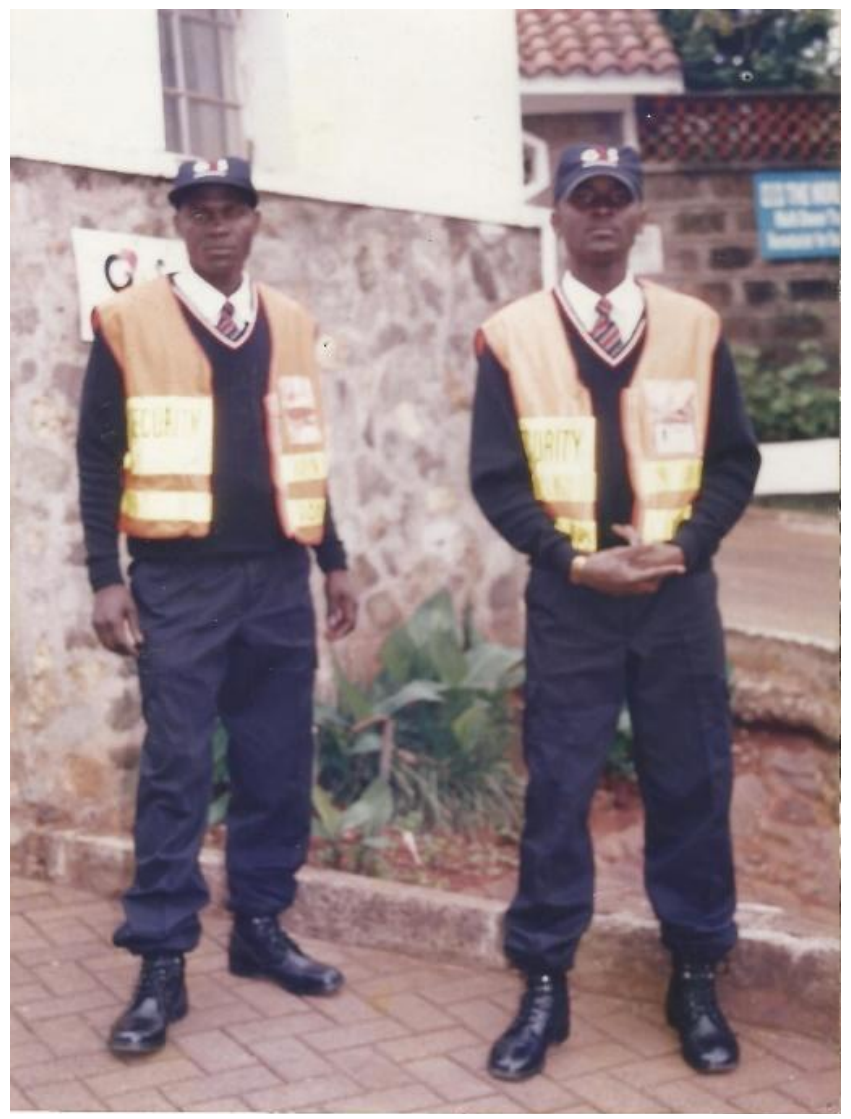

Figure 2 - Visible Presence of the Security Guards
This conspicuous presence of the commercial security guards reassures the citizens of their safety. From a theoretical perspective, they represent the concept of a present guardian, a key aspect in foiling crime. Security guard's visibility plays a preventive role in national security by ensuring freedom from fear of criminality.

\section{Detection of Criminal and Harmful Activities by the Electronic Devices}

The detection of criminal and harmful activities by the electronic devices, was the second most identified effect of commercialized security on national security, with 348 (93\%) respondents. Since not all electronic devices stop risks and dangers, the rationality underlying their usage is the detection of criminal activities. The detection capabilities of the alarms and electronics were mentioned. A respondent had this to say...

"These days, most establishments have installed CCTVs. I would be very comfortable being in an establishment that has them as I know that they detect some criminal activities".

Restaurants, receptions, supermarkets, hospitals, private parking, and most private facilities, have embraced the culture of installing CCTVs. Due to the detection abilities of the CCTVs, customers and visitors to various establishments are feeling secured and protected. This has a ripple effect of increased national security. Whether being monitored by a controller or not, the CCTVs tends to give assurance to the general public of their security. CCTVs have hardened places where crime would have taken place by making them less attractive to criminals. This confirms that some offenders were put off by targets hardened with the installation of surveillance especially with the electronic devices [55]. Drawing from the routine activity theory, for crime to occur, three elements must be present: the presence of a criminally motivated person, suitable target or potential victim, and absence of capable guardians to discourage crime. Therefore, the presence of the CCTVs eliminates the third element, which is the absence of capable guardians. The CCTVs offer the presence of a capable guardian that discourages crime. In essence, the presence of CCTV aims to impede potential offenders carrying out their intended activities, by placing psychological and physical barriers in their way. The perception that their identity could be determined, discour- 
ages the "would be" criminals, because of fear of being accosted by law enforcement. This discouragement, whether real or perceived, serves to enhance national security.

The findings of this study show that the detection abilities of commercial security measures are taken in advance to avert possible criminal and harmful activity. Therefore, national security is boosted with the risk-mitigating precaution of these detection measures of commercial security. One respondent had this to say...

"Most of the establishments have installed CCTVs, and we have been seeing on social media of the criminals captured on them as they engage in unlawful activities. Even though the incidents are reviewed later after happening, at least the suspects are identified and the police can arrest them after investigation".

The respondent acknowledged the usefulness of the CCTV cameras as a commercial security device that detects criminal and harmful activities. Even though some CCTVs monitors are not manned, they are replayed when making followups when an incident has happened. Field observation (appendix II) showed that most of the premises like hotels, supermarkets, hospitals, and bars, appeared well organized with their arrangements of the CCTV cameras. There were CCTVs installed on the entrances to the establishments, others capturing most of the inside, and also at the back. It has also been found that there was a tremendous reduction of the overall risk of burglary amongst facilities with a CCTV system [44; 58].

Some electronic devices like luggage $\mathrm{x}$-ray detect risks and dangers. In the words of one of those interviewed...

"I remember this unfortunate incident when I had accidentally left my Tactical Knife in the backpack. As it went through the x-ray machine in one of the government buildings, and it was detected. I had to have a quick explanation for it but I had to leave the bag with them as I accessed the inside of the building".

This goes a long way to show that, the commercial security industry's use of electronic devices can detect risks and dangers. Security personnel is trained to use the security $\mathrm{x}$-ray machine to check luggage and look any for suspicious items (Figure 3).
A security $\mathrm{x}$-ray baggage scanner, therefore, helps keep visitors, assets, and facilities safe. Weapons, explosives, and narcotics are just some of the illegal goods that security personnel has to deal with. Buildings and premises must be secured to keep both public and hosts safe. From the field observation, security personnel appeared knowledgeable using the security x-ray scanners as shown in Figure 3.

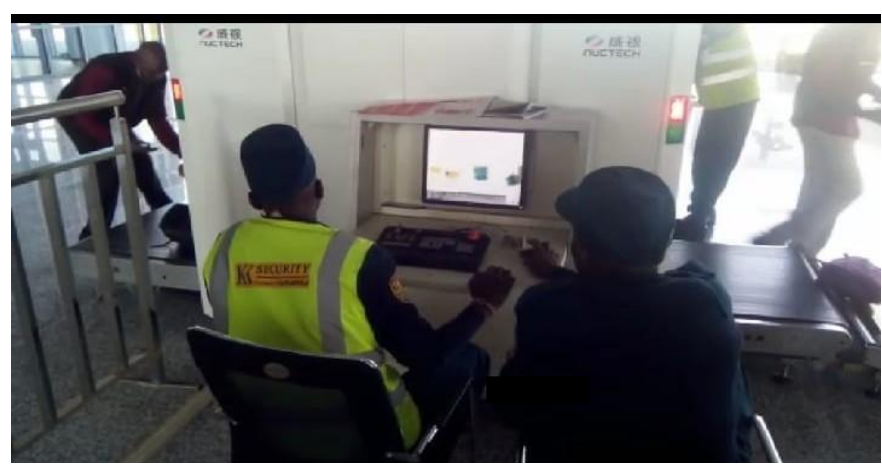

Figure 3 - Security Guards Operating a Security X-Ray Machine

To improve the physical security of buildings and facilities, one of the best options has been the use of turnstiles to control employee and visitor access. Some electronic devices like the turnstiles delay risks and dangers. A respondent explained...

"I came across that machine that allows one person at a time to go in after you have swiped your card. We were several people going for a meeting in the building and we just had to wait as each one of us was cleared and allowed in. Despite the delay that we experienced, it looked a very polite way to control access".

Turnstiles make available high-level access and egress regulator by either detecting and deterring unsanctioned passes. Differently from doors, turnstiles can restrict the total of persons who can pass using each offered credential, and also regulate the route of the passageway. To enter through a turnstile, people have to offer a current credential. This ensures that an unauthorized person is not able to gain access through tailgating, and therefore denies passage to any person who would be a security risk to an organization. This secures a facility so that any people considered to pose danger and harm can be barred. As Furedi observed in his book 'Culture of Fear', electronic technologies such as turnstiles have been found to reduce the fear of crime and crime [16]. 
Observations made by the researcher in the field indicated that several types of turnstiles are used to assist in access control. Others are controlled by a digital card that each visitor is given to swipe. They, therefore, easily meet the security enhancement requirements and as a result enhance the security of today's modern commercial and private amenities. Reflecting on the Concentric Ring Theory, the turnstile is part of the outer security ring that denies passage to an aggressor. The implication of this is that harm and danger are being kept at bay from the people and their property.

Other electronic technologies that can detect risks and dangers include the keyless door locks (digital/smart locks). A consumer respondent pointed out that...

"Most people will never realize the importance of biometric door until that time they wake up and realize that their stores or shop are swept clean. That is when they decide to incur a one-time expense and invest in biometric doors".

From the narrative, keyless door locks are used to detect access in restricted areas. Key fewer doors are a technique that has been embraced by customers of commercial security services. The addition of keyless door locks has reduced the risk of theft from facilities by making them more difficult to access. This method has reduced the suitability of targets that would otherwise be attractive to likely offenders. Also, keyless door locks act as a detection technology, which seeks to increase the cost of carrying out criminal action since detection relies on the perception of the potential perpetrator. The results tend to support the broad expectations of national security. As had previously been observed that, the presence of an alarm and electric devices discourages burglary attempts on facilities [7; 21]. Similarly, Preventing Repeat Victimization found out that, burglary deterring devices prevented a repetition of burglary [19].

Further, the more alarm and electric devices fitted to a facility, the lower the risk of break-ins [58]. Similarly, estimates of the extent of use of crime prevention innovations - metal detectors in schools, baggage screening at airports, bulletproof teller windows at banks, and electronically controlled automatic security access gate systems are difficult to obtain, but it is obvious that crime prevention technology has been the driving force leading to crime prevention and crime control strategies, both by individual citizens and concerned groups [12]. This effect consequently, contributes to an enhancement of national security as the people and their properties are kept secure from harm and danger.

\section{Intervening in Stopping Crime and Harm}

The intervention in stopping criminal activities before or when it is happening was the third most identified effect of commercialized security on national security with 297 (79.4\%) respondents mentioning it. Security personnel can intervene in stopping crime in places where they are deployed, due to their control and authority over the areas. The public and the offenders are aware of this effect of the personnel of the security industry.

They may intervene in private places and also public places such as airports, hospitals, schools, colleges, hotels, apartments, gated communities, and supermarkets. This effect benefits society directly and complements state security agents in security management. The commercial security personnel can intervene in stopping a crime from being committed as part of their responsibilities [3].

Since most of the office and commercial facilities are fitted with electronic devices, they inform when a crime is occurring. One of the customer participants narrated...

"Attempted break-in at night is something that most of the industries have to deal with. We get calls at night from our contracted alarm response team that there had been an attempted break-in at our facility and they have repulsed the intruders"

A commercial security manager respondent explained...

"As an integrated service, alarm response teams are valued for money for those using it".

In the words of a member of an alarm response team...

"Most of the alarm activations are during the night. But we can respond and neutralize the threats".

It is acknowledged that alarm response as a component of the services of commercial security has been taken up by citizens due to its ability to be able to intervene and stop breaches of security. In isolation, security systems measures may have a limited deterrent effect. However, 
due to the integration with alarm response measures, the targets (assets) have been made less attractive to those to steal or cause any danger. This is due to the increased risks of being apprehended and neutralized. The alarm response team strategies for that reason are used to reduce the opportunities for crime due to increased formal surveillance and patrols. They have also increased controls on access or exits for intruders and offenders. As Gerasimoski argued in his study on Obstacles to Stability in the Namibian state and Society, an alarm response strategy is practiced as preventive to crime and insecurity [18]. This practice of intervening to stop crime complements national state security as it keeps people and their property safe.

This is reinforced by the third premise of the theory of security governance, which proposes that the state's exclusive provider of security to be supported by other actors who will inject in efficiency and cost-effectiveness. The commercial security industry brings inefficiency in security incidents responses, as it has invested extensively with the right security equipment and trained personnel. The commercial security industry also brings in cost-effectiveness by ensuring that the state security agencies are released to concentrate their resources to serve the areas which are not habited by those able to buy security services. All this serves to intervene in stopping crimes like trespassing, vandalism, criminal and harmful activities at properties.

Furthermore, observations from the field indicated that most of the alarm response teams appeared well equipped (appendix II). Most of the response vehicles were equipped with, first aid response kits, rechargeable torches, high visibility vests, traffic control equipment, back-to-base radios, digital cameras, helmets, batons, shields, fire extinguishers, axes, heavy-duty hammers, ladders, and fuel cards. When probed further on the rationale for all the equipment, the alarm and response crew explained to the researcher that they were appropriate in responding to either criminal activities, any distress, or accidents. Some explanations given were that the first aid kits are necessary so that you can treat injuries and ailments that happen to people, and the first aid kit can help reduce the severity of the injury or the risk of infection. Back-to-base radios give observations and information in real-time, and hence not necessitating to make a personal report.
Fire extinguishers are the first line of defense against fires and every so often contains or extinguish fires, averting exorbitant destruction. Fire extinguishers can make a difference between a minor fire incident and devastation. Heavy-duty hammers and axes are used to break through windows of vehicles involved in accidents or dislodge doors from the hinges to rescue the occupants. They are also used to break through obstacles like closed doors and gates so that the security response crew can reach the people or asset that is in distress.

Batons and shields are, in general, intended to be used to control unruly offenders, to safeguard the security crew from attacks with blunt or sharp weapons, and also thrown weapons. They can also be applied as close contact fighting weapons to push back offenders. Ladders are by and large used to scale perimeter walls so that the security alarm response crew can be able to access a facility whose access points are locked or blocked. In essence, commercialized security provides the possibility of intervening in stopping crime and harm.

\section{Intelligence on Criminal Activities through Surveillance}

The ability of the commercial security agents to gather intelligence on criminal activities through surveillance was the fourth identified effect of commercialized security on national security with 257 (68.7\%) of the respondents admitting it. Due to the surveillance nature of their jobs, the commercial security guards get to see and notice events that would pass the general public. One of the managers of the security firms interviewed explained...

"On several occasions, we have shared information with the police on crimes that have been planned to happen. This intelligence is mostly passed to us by our security guards".

A security manager of the consumers also had this to say...

"We have alerted our neighbors who do not see the need for security guards about plans to have their warehouses raided. In normal circumstances, we do not let the guards securing our place to intervene with what is happening in a neighbor's place. But they can inform us and we share with the relevant authorities".

In the words of one security guard respondent... 
"We see things, we hear a lot, and we know much about the security of the places around where we are stationed. And even the police know that and some of them use the knowledge we have while policing. Sometimes, we are the silent and passive eye of the police".

The public too is acknowledging the ability of commercial security personnel of having intelligence on criminal activities. One general public respondent stated that...

"The reason why we rely on them for information is that they have facts on the most unusual activities. Therefore, they can advise us accordingly".

From the responses, the theme of having information in advance on criminal activities is recurring. The commercial security personnel while on duty, receive details from their sources on the kind of criminal activities in their vicinity. Also, through their alertness and surveillance, security personnel notice unusual activities. This is shared with the state security agents, mostly the police, who could use the information to act to deter criminality. Commercial security is therefore a force multiplier: additional sets of ears and eyes on the street that can listen, observe, and report developments. This further helps to enhance the safety and security of communities. The intelligence on criminal activities by commercial security agents improves the security of people [36].

This draws on the second premise of security governance theory that recommends the need for states to increase collaboration with nonstate actors such as international organizations, NGOs and commercial organizations to combat the new form of insecurity. These networks, improve the quality of security for people and properties by ensuring that even if there is a surge of likely offenders in the community, they will find a matched increase in the deployment of suitably trained security personnel who will be in a position to gather intelligence on them and defend the community.

The network analysis theory adds that a partnership involving state security agencies and the commercial security industry is needed because they share an interest in security issues. Working together whether through formal or informal arrangements is in the long run supposed to ensure the safety of the citizens of Kenya.

With the current trends of insecurity where the enemy is invisible, the full tactical turnout and automatic weapons power cannot eliminate them. Intelligence on criminal activities through surveillance, in the long run, will ensure the safety of the citizens of Kenya and their properties.

\section{Creating a Culture of Security and Crime Awareness}

The creation of a culture of security and crime awareness was the least identified effect of commercialized security on national security by the citizens. It was identified with 121 (32.4\%) of the respondents. This is done through various ways of communication. One of the managers of an organization subscribed to the commercial security services explained...

"We get emails advising us on the current situation in the country, and the precautions to take. But in very crucial moments, we receive text messages advising us on volatile situations like riots and demonstrations on specific roads".

A manager of a commercial security firm agreed that...

"We have weekly emails to our customers, informing them of the current security situation in the country. We also send instant messages advising them on any volatile situations on the road and towns areas especially during the 2017 general election".

Both respondents acknowledge the usefulness of the emails and text messages that are sent by the commercial security providers. The emails are more general, giving out a report or analysis on the current and expected security situation in the country. Whereas the text messages are meant to provide real-time updates, such alerts might contain critical, emergency-related information including instructions and recommendations in real-time by the security service providers. Information includes riots and demonstrations, severe weather warnings, significant public road closures, accidents, and other emergency conditions. That way, the subscribers and their workers make timely decisions based on the best information available, increasing their safety, and boosting an organization's security and safety. The service providers always confirm notification delivery with "by recipient" reports.

The ability of the commercial security firms to have emergency-related information for various places affords the advantage of deploying personnel in areas of most security needs. Apart 
from their personnel on the ground, some of the information and intelligence comes from the state security agents. For example, during the 2017 election period in Kenya when there were incidences of insecurity in some parts of the country, customers received security updates that governed their movements and activities. When the customers would get text messages on insecurity incidents, they would also share the same with their family and friends. In the long run, some of the recipients of the text messages were not only those who were subscribed to customers but the general public. Sharing of text messages and emails concerning security and crime issues has created a culture of security and crime awareness among the citizens. As a result, the commercial security industry provides security for people and their assets efficiently and cost-effectively through text messages and emails. Creating a culture of security and crime awareness is a positive effect of the commercial security industry on national security that has promoted the safety and security of the citizens.

In principle, commercial security delivers allinclusive effects that cover the broader concept of security that not only boosts national security but also ensures freedom of the nationalities.

Drawing from the descriptive statistics and the discussion based on observations and qualitative data from the field, one can infer that commercial security though a profit-making organization plays an invaluable role in national security. However, descriptive and qualitative data may not provide a solid base for concluding. Therefore, there was a need to run a regression to determine the effects.

\section{Regression of the Effects of Commercialized Security}

Multiple regression was also performed to summarize the results of the descriptive discussion on the effects of commercial security. The regression used the five identified effects of commercialized security to determine how they may be associated with the dependent variable (national security). Several assumptions of multiple regression analysis were tested to ensure that the analysis was reliable and valid (Appendix 3). The results of the multiple regression analysis are displayed in Table 1 below.

Table 1 - A Regression Analysis to Determine the Contribution of the Effects of Commercial Security Services on National Security

\begin{tabular}{|l|c|c|c|c|c|c|c|}
\hline \multirow{2}{*}{ Model } & \multicolumn{2}{|c|}{$\begin{array}{c}\text { Unstandardized } \\
\text { Coefficients }\end{array}$} & $\begin{array}{c}\text { Standardized } \\
\text { Coefficients }\end{array}$ & \multirow{2}{*}{$\mathrm{t}$} & \multirow{2}{*}{ Sig. } & \multicolumn{2}{c|}{$\begin{array}{c}\text { Collinearity } \\
\text { Statistics }\end{array}$} \\
\cline { 2 - 4 } \cline { 5 - 8 } & $\mathrm{B}$ & Std. Error & Beta & & & Tolerance & VIF \\
\hline (Constant) & -.163 & .112 & & - & .144 & & \\
\hline $\begin{array}{l}\text { Visible presence that discourages } \\
\text { criminal activities }\end{array}$ & .372 & .046 & .383 & 8.129 & .000 & .487 & 2.052 \\
\hline $\begin{array}{l}\text { Detection of criminal and harmful } \\
\text { activities by the electronic devices }\end{array}$ & .250 & .048 & .257 & 5.156 & .000 & .436 & 2.294 \\
\hline $\begin{array}{l}\text { Intervening in stopping crime and } \\
\text { Harmful activities }\end{array}$ & .213 & .040 & .194 & 5.333 & .000 & .818 & 1.222 \\
\hline $\begin{array}{l}\text { Intelligence on criminal activities } \\
\text { through surveillance }\end{array}$ & .176 & .042 & .159 & 4.206 & .000 & .755 & 1.324 \\
\hline $\begin{array}{l}\text { Creating a culture of security and } \\
\text { crime awareness }\end{array}$ & .086 & .038 & .076 & 2.269 & .024 & .965 & 1.036 \\
\hline
\end{tabular}

Notes: Dependent Variable: National Security

From the table, the overall regression model was significant $\left(\mathrm{F}(5,368)=111.42, \mathrm{p}<.001, \mathrm{R}^{2}=.231\right)$. The results of the regression indicated that the model explained $23.1 \%$ of the variance. Overall, the effects combined contribute $23.1 \%$ on national security. When we take the five predictors as a group, they predict national security signifi- cantly, but each of the effects/predictors accounts for unique variance in national security.

Visible presence that discourages criminal activities positively impacts national security $(\mathrm{B}=.372$, $\beta=.383, P=.001)$. Therefore, a visible presence that discourages criminal activities adds $37.2 \%$ 
of the $23.1 \%$ that the effects of commercial security services contribute to national security.

The P-value is .001, which is less than the standard alpha of .05 , suggests that the relationship between the two variables is positive. For every 1 standard deviation unit increase in visible presence that discourages criminal activities, we would expect a corresponding 0.383 standard deviation unit increase in national security. Therefore, a visible presence that discourages criminal activities is a significant predictor of national security.

The results for the detection of criminal and harmful activities by the electronic devices showed that it had a significant contribution to national security (Table 1 above). Detection of criminal and harmful activities by the electronic devices significantly and positively impacts national security $(B=.250, \beta=.257, P=.001)$. Therefore, it contributes 25 percent of the 23.1 percent that the effects of commercial security services contribute to national security.

For the intervention in stopping crime and harm, it had a significant contribution to national security (Table 1 above). Intervening in stopping crime positively impacts national security $(\mathrm{B}=.213, \beta=.194, \mathrm{P}=.001)$. Therefore, it contributes 21.3 percent of the 23.1 percent that the effects of commercial security services contribute to national security.

The results for intelligence on criminal activities through surveillance had a significant contribution to national security (Table 1 above). Intelligence on criminal activities through surveillance positively impacts national security $(B=.176$, $\beta=.159, P=.001)$. Therefore, it contributes 17.6 percent of the 23.1 percent that the effects of commercial security services contribute to national security.

Further results indicate that creating a culture of security and crime awareness showed that it had a significant contribution to national security (Table 1 above). Creating a culture of security and crime awareness positively impacts national security $(B=.086, \beta=.076, P=.024)$. Therefore, it contributes 8.6 percent of the 23.1 percent that the effects of commercial security services contribute to national security. A culture of security and crime awareness offers an exclusive alteration to national security. Individuals learn selfcare and plan their activities to avoid areas that could compromise security, thus deterring the criminals.
The findings of this study indicate that visible presence that discourages criminal activities, detection of criminal and harmful activities by the electronic devices, intervening in stopping crime and harm, intelligence on criminal activities through surveillance, and creating a culture of security and crime awareness are some of the effects of commercial security on national security.

The commercialized security though motivated by profit-making plays a significant role that enhances state capacity in the provision of security as well as contributes to the safety of citizens. Therefore, contrary to the popular belief by some scholars that, commercial security displaces insecurity to other areas [23], this study found the availability of various services offered by commercial security edifies security hence creating feelings of safety not only to the customer buying the services but also to the surrounding environments. This greatly contributes to the safeguarding of people (citizens and visitors) and their property leading freedom that inculcates social-economic development. Also, the possible networking between commercialized security and state security has the potential to offer effective security if the commercialized security in Kenya is effectively legitimized and regularized. Accordingly, a collaboration between different actors in security in this case the state and nonstate actors holds the potential of pooling resources together and coordinating actions in pursuit of security. Therefore, based on the findings, this study argues alongside other scholars that characterize a network of actors with a common goal can create links to help them pursue shared interests and values (reduction and elimination of insecurity) $[4 ; 27 ; 34]$

\section{CONCLUSION}

Based on the discussion, the study recommends that:

1. The effects of commercialized security on national security bring to fore the huge responsibility the industry is endowed with. Consequently, there should be favorable mechanisms in the country that can oversee the continuous development of the industry. The favorable mechanisms can only be realized through the consultation of the stakeholders: the commercial security industry, the citizens, and the state.

2. The Private Security Regulation Authority needs to start implementing some of the re- 
quirements that are in the PSRA No. 13 of 2016, which are meant to streamline the industry in terms of the training of the security guards, remunerations of the security guards, minimum requirements for recruitment and working environments. This is so that the country and citizens can benefit from the basis of which the authority was formed.

3. The amendment of Section 53 of the PSRA Act which prohibits the use of arms by the commercial security personnel. This would allow the security guards to be armed with firearms to enable them to match and even outmatch the current challenge they are facing armed criminals. The regulator and the private security providers need to make modalities on how the same can be implemented so as not to become a source of insecurity for the citizens, but instead, it should be able to enhance and contribute positively to national security.

4. The study also recommends that the consumers should use the platform that has been created by the PSRA No. 13 of 2016 to express their experiences, either limitations or best practices, to the PSRA authority. They should also make known to the authority of their expectations.

Based on the scope and the findings for this study, the following are recommendations for future research:
1. The research limited itself to the commercialized security in Nairobi City County. However, several similarities in the industry were noted, especially through literature. It would be useful to extend this study to other counties, to determine to what extent the findings are applicable in Kenya.

2. There should be a study to evaluate the impact of the commercialized security industry on national security exclusively from the perspectives of the state security agencies in Kenya. These would include the police and other state security organs. It would be of interest to know what stakeholders perceive of their fellow fighters of insecurity.

3. A further study should explore the collaboration among the commercial security industry and the national security organs to improve the security of people and their property.

\section{ACKNOWLEDGMENTS}

I appreciate a good friend and mentor Dr. Merecia Sirera Ann, of the department of security and correctional science, and the school of security, diplomacy, and peace studies at Kenyatta University for standing by me. I also acknowledge the whole fraternity of the school of security, diplomacy, and peace studies at Kenyatta University for their effort in modeling security studies.

\section{REFERENCES}

1. Abrahamsen, R., \& Leander, A. (Eds.). (2015). Routledge Handbook of Private Security Studies. London: Routledge. doi: 10.4324/9781315850986

2. Abrahamsen, R., \& Williams, M. (2005, January). The Globalization of Private Security. Country Report: Kenya. Retrieved from https://users.aber.ac.uk/rbh/privatesecurity/country\%20reportkenya.pdf

3. Adegboyega, K. (2012). Analyzing the Evolution of Private Security Guards and their Limitations to Security Management in Nigeria. African Journal of Criminology and Justice Studies, 5(1-2), 3248.

4. Arquilla, J., \& Ronfeldt, D. (1996). The Advent of Netwar. Retrieved from https://www.rand.org/pubs/monograph_reports/MR789.html

5. Asomah, J. (2017). Understanding the Development of Private Policing in South Africa. African Journal of Criminology and Justice Studies, 10, 61-82.

6. Berg, J. (2007). The Accountability of South Africa's Private Security Industry: mechanisms of control and challenges to effective oversight. Retrieved from http://eprints.gla.ac.uk/170063/

7. Kuhns, J., Blevins, K., \& Lee, S. (2012). Understanding Decisions to Burglarize from the Offender's Perspective. Retrieved from https://www.researchgate.net/publication/268444817_Understanding_Decisions_to_Burglariz e_from_the_Offender's_Perspective 
8. Boemcken, M. (2011). Commercial Security and Development: Findings from Timor-Leste, Liberia and Peru. Retrieved from https://www.bicc.de/uploads/tx_bicctools/brief45.pdf

9. Borzel, T. A. (1998). Organizing Babylon - On the Different Conceptions of Policy Networks. Public Administration, 76(2), 253-273. doi: 10.1111/1467-9299.00100

10. Baker, B. (2013). Security Beyond the State: Private Security in International Politics. International Peacekeeping, 20(1), 118-119. doi: 10.1080/13533312.2012.761852

11. Business Executives for National Security. (2016). Private Partnerships, Public Safety: How a More Networked Approach to Public Safety Can Improve Our Ability to Navigate a Complex Threat Environment. Retrieved from https://www.bens.org/file/PrivatePartnerships_PublicSafety.pdf

12. Byrne, J., \& Marx, G. (2019). Technological Innovations in Crime Prevention and Policing. A Review of the Research on Implementation and Impact. Cahiers Politiestudies Jaargang, 20, 17-40.

13. Cabral, S., \& Saussier, S. (2012). Organizing Prisons through Public-Private Partnerships: a crosscountry investigation. BAR - Brazilian Administration Review, 10(1), 100-120. doi: 10.1590/s1807-76922012005000010

14. Cohen, M. (2014, April 7). Crime-Busting G4S Faces South Africa Private Security Curbs. Retrieved from http://www.bloomberg.com/news/2014-04-06/crime-busting-g4s-at-risk-as-southafrica-curbs-private-security.html

15. Feng, B. (2013). Chinese Bodyguards, When Police Won't Do. Retrieved from

http://sinosphere.blogs.nytimes.com/2013/10/14/chinese-bodyguards-when-police-wont-do/

16. Furedi, F. (2002). Culture of Fear. Continuum. London: $\mathrm{n}$.d.

17. George, B., \& Kimber, S. (2014). The History of Private Security and Its Impact on the Modern Security Sector. The Handbook of Security, 21-40. doi: 10.1007/978-1-349-67284-4_2

18. Totemeyer, G. (2013). Obstacles to Reconciliation and Stability in the Namibian State and Society. Windhoek: Namibia Institute of Democracy.

19. Grove, E., Farrell, G., Farrington, D., \& Johnson, D. (2012). Preventing Repeat Victimization: A Systematic Review. The Swedish National Council for Crime Prevention. Stockholm, Sweden: BRA.

20. Gumedze, S. (2015). Promoting partnerships for crime prevention between state and private security providers in Southern Africa. Retrieved from https://idl-bncidrc.dspacedirect.org/bitstream/handle/10625/54416/IDL54416.pdf? sequence $=1$ \&isAllowed $=y$

21. Hearnden, L., \& Magill, C. (2004). Decision-making by House Burglars: Offenders' Perspectives. London: Home Office.

22. Inyang. D and Ubong. A (2013). Policing Nigeria: A case for partnership between formal and informal police institutions. Merit Research Journal of Art, Social Science and Humanities, 1(4), 53-58.

23. Jackson, P., \& Beswick, D. (2014). Conflict, Security and Development: An Introduction. London: Routledge.

24. Kaguru, K., Ombui, K. (2014). Factors Affecting Performance of Private Security Firms in Nairobi County: A Case Study of G4S Security Services (K) Ltd. International Journal of Science and Research, 3(2), 281-286.

25. Kenya National Commission on Human Right. (2014). A country under siege: the state of security in Kenyan. Occasional report 2010-2014. Retrieved from http://www.knchr.org/Portals/0/CivilAndPoliticalReports/The\%20State\%20of\%20Security\% 20in\%20Kenya.pdf

26. Kiama. S and Bor. E (2015). Private Security services and crime control in Karen location, Nairobi County, Kenya. Journal of Humanities and Social Science, 20(10), 84-90. 
27. Krahmann, E. (2018). The market for ontological security. European Security, 27(3), 356-373. doi: 10.1080/09662839.2018.1497983

28. Kenya Security Industry Association. (2005). About Kenya Security Industry Association. Retrieved from http://www.ksia.co.ke

29. Litavski, J. (2012). The Challenges of Private Security Sector, Quarterly of center for Euro-Atlantic studies. Retrieved from https://www.ceas-serbia.org/images/tromesecnik/New-Century-No-2Jan-Litavski.pdf

30. Louw, G. (2010). South African Defence Policy and Capability: The Case of the South African National Defence Force (Master's thesis), Stellenbosch University. Retrieved from https://scholar.sun.ac.za/bitstream/handle/10019.1/85766/louw_south_2013.pdf?sequence= 1

31. Githimi, S., \& Bor, E., \& Appolos, M. (2017). How the availability of private security services assist in crime control in Nairobi County, Kenya. Global Journal of Arts, Humanities and Social Sciences, 5(1), 51-61.

32. Elahi, M. (2013). Summary of Social Contract Theory by Hobbes, Locke and Rousseau. SSRN Electronic Journal. doi: 10.2139/ssrn.2410525

33. Markusen, A. R. (2003). The Case Against Privatizing National Security. Governance, 16(4), 471501. doi: 10.1111/1468-0491.00225

34. Minear, L., van Baarda, T., \& Sommers, M. (2000). NATO and Humanitarian Action in the Kosovo Crisis. Retrieved from https://www.unhcr.org/partners/partners/3bb051c54/natohumanitarian-action-kosovo-crisis-occasional-paper-36.html

35. Mkilindi, A. (2014). Assessment of the role of Private Security Companies in the enhancement of public security (Master's dissertation). Retrieved from

http://scholar.mzumbe.ac.tz/bitstream/handle/11192/1046/MSc_HRM_Aisha\%20M.\%20Mkili ndi_2014.pdf?sequence $=1$

36. Montgomery, R., Griffiths, T. (2015). The Use of Private Security Services for Policing. Research report: 2015-R041. Retrieved from https://www.publicsafety.gc.ca/cnt/rsrcs/pblctns/archive2015-r041/2015-r041-en.pdf

37. Morrow, R., \& Torres, C. (2003). The State, Globalization, and Educational Policy. New York: Routledge.

38. Mutonyi, G. P., \& Sirera, A. (2018). Commercial Security's' Effect on Security of Kenyans in Private Venues. Emerging Science Journal, 2(4). doi: 10.28991/esj-2018-01142

39. Cabinet Secretariat. (2013). National Security Strategy. Retrieved from https://www.cas.go.jp/jp/siryou/131217anzenhoshou/nss-e.pdf

40. Nemeth, C. (2012). Private Security and the Law (4th ed.). New York: Elsevier.

41. Noaks, L. (2000). Private cops on the block: A review of the role of private security in residential communities. Policing and Society, 10(2), 143-161. doi: 10.1080/10439463.2000.9964837

42. Ondrejcsák, R. (2014). Introduction to Security Studies. Centre for European and North Atlantic Affairs. Bratislava: n. d.

43. Overseas Security Advisory Council, Bureau of Diplomatic Security. (2017, April, 27). Kenya 2017 Crime \& Safety Report. Retrieved from https://www.osac.gov/Content/Report/288c4b79-1f424e0d-ae9e-15f4ae15fe2b

44. Pease, K., \& Gill, M. (2011). Home Security and Place Design: Some Evidence and its Policy Implications. Retrieved from https://www.securedbydesign.com/guidance/research-casestudies-guidance/home-security-and-place-design 
45. Lottholz, P., \& Lemay-Hébert, N. (2016). Re-reading Weber, re-conceptualizing state-building: from neo-Weberian to post-Weberian approaches to state, legitimacy and state-building. Cambridge Review of International Affairs, 29(4), 1467-1485. doi: 10.1080/09557571.2016.1230588

46. Pienaar, E. (2014). Serious crime as a national security threat in South Africa since 1994. Retrieved from

https://repository.up.ac.za/bitstream/handle/2263/46070/Pienaar_Serious_2014.pdf?sequenc $\mathrm{e}=1$ \&isAllowed $=\mathrm{y}$

47. Prenzler, T., \& Milroy, A. (2012). Recent inquiries into the private security industry in Australia: Implications for regulation. Security Journal, 25(4), 342-355. doi: 10.1057/sj.2012.2

48. Prenzler, T., \& Sarre, R. (2012). The Evolution of Security Industry Regulation in Australia: A Critique. International Journal for Crime, Justice and Social Democracy, 1(1). doi: 10.5204/ijcjsd.v1i1.72

49. Private Security Industry Association. (2018). About Private Security Industry Association. Retrieved from http://www.psia.com

50. Robertson, L. (2008). Remaking the World: Neoliberalism and the Transformation of Education and Teachers' Labor. In M. Compton, L. Weiner (Eds.), The Global Assault on Teaching, Teachers, and their Unions Stories for Resistance (pp. 11-27). New York: Palgrave Macmillan.

51. Sarkesian, S., Williams, J., \& Cimbala, S. (2013). US National Security: Policymakers, Processes and Politics. Boulder: Lynne Rienner.

52. Sirera, M. (2014). Education and Skill formation for economic development in Kenya. International Journal of Education and Research, 2(9), 1-14

53. Sparrow, M. (2014). Managing the Boundary between Public and Private Policing. New Perspectives in Policing. Retrieved from https://www.ncjrs.gov/pdffiles1/nij/247182.pdf

54. Strom, K., et al. (2010). The Private Security Industry: A Review of the Definitions, Available Data Sources, and Paths Moving Forward. Retrieved from https://www.ncjrs.gov/pdffiles1/bjs/grants/232781.pdf

55. Taylor, E. (2013). Honour among thieves? How morality and rationality influence the decisionmaking processes of convicted domestic burglars. Criminology \& Criminal Justice, 14(4), 487502. doi: $10.1177 / 1748895813505232$

56. National Council for Law Reporting with the Authority of the Attorney General. (2008). The Constitution of Kenya. Retrieved from https://kfcb.co.ke/wpcontent/uploads/2016/07/Constitution.pdf

57. National Police Service. (2018). Annual Crime Report 2018. Retrieved from http://www.nationalpolice.go.ke/crime-statistics.html\#

58. Tseloni, A., Thompson, R., Grove, L., Tilley, N., \& Farrell, G. (2017). The effectiveness of burglary security devices. Security Journal, 30(2), 646-664. doi: 10.1057/sj.2014.30

59. U. S. Department of Justice. (2009). Operation Partnership. Trends and Practices in Law Enforcement and Private Security Collaborations. Retrieved from http://www.ilj.org/publications/docs/Operation_Partnership_Private_Security.pdf

60. United Nations Office on Drugs and Crime. (2014). State Regulation concerning Civilian Private Security Services and their Contribution to Crime Prevention and Community Safety. Retrieved from https://www.unodc.org/documents/justice-and-prisonreform/crimeprevention/Ebook0.pdf

61. Vileikienè, E., \& Janušauskienè, D. (2016). Subjective Security in a Volatile Geopolitical Situation: Does Lithuanian Society Feel Safe? Journal on Baltic Security, 2(2), 109-143. doi: 10.1515/jobs2016-0047

62. Wibben, A. (2011). Feminist Security Studies: A Narrative Approach. London: Routledge. 
63. Khong, W. (2013). 'Persons of Versatility': Private Security Officers and Private Policing in Residential Estates in Hong Kong (Doctoral thesis), Institute of Criminal Justice Studies University of Portsmouth. Retrieved from https://pdfs.semanticscholar.org/e918/5275263beb0d4efb9913f3ec5d7682ae576d.pdf

64. Wolmar, C. (2013). The Great Railroad Revolution: The History of Trains in America. New York: PublicAffairs

\section{APPENDIX}

Appendix 1 - Krejcie and Morgan sample size table

\begin{tabular}{|c|c|c|c|c|}
\hline $\mathrm{N}-\mathrm{n}$ & $\mathrm{N}-\mathrm{n}$ & $\mathrm{N}-\mathrm{n}$ & $\mathrm{N}-\mathrm{n}$ & $\mathrm{N}-\mathrm{n}$ \\
\hline $10-10$ & $100-80$ & $280-162$ & $800-260$ & $2800-338$ \\
\hline $15-14$ & $110-86$ & $290-165$ & $850-265$ & $3000-341$ \\
\hline $20-19$ & $120-92$ & $300-169$ & $900-269$ & $3500-346$ \\
\hline $25-24$ & $130-97$ & $320-175$ & $950-274$ & $4000-351$ \\
\hline $30-28$ & $140-103$ & $340-181$ & $1000-278$ & $4500-354$ \\
\hline $35-32$ & $150-108$ & $360-186$ & $1100-285$ & $5000-357$ \\
\hline $40-36$ & $160-113$ & $380-191$ & $1200-291$ & $6000-361$ \\
\hline $45-40$ & $170-118$ & $400-196$ & $1300-297$ & $7000-364$ \\
\hline $50-44$ & $180-123$ & $420-201$ & $1400-302$ & $8000-367$ \\
\hline $55-48$ & $190-127$ & $440-205$ & $1500-306$ & $9000-368$ \\
\hline $60-52$ & $200-132$ & $460-210$ & $1600-310$ & $10000-370$ \\
\hline $65-56$ & $210-136$ & $480-241$ & $1700-313$ & $15000-375$ \\
\hline $70-59$ & $220-140$ & $500-217$ & $1800-317$ & $20000-377$ \\
\hline $75-63$ & $230-144$ & $550-226$ & $1900-320$ & $30000-379$ \\
\hline $80-66$ & $240-148$ & $600-234$ & $2000-322$ & $40000-380$ \\
\hline $85-70$ & $250-152$ & $650-242$ & $2200-327$ & $50000-381$ \\
\hline $90-73$ & $260-155$ & $700-248$ & $2400-331$ & $75000-382$ \\
\hline $95-76$ & $270-159$ & $750-254$ & $2600-335$ & $100000-384$ \\
\hline
\end{tabular}

Appendix 2 - Observational check lists Results

\begin{tabular}{|l|c|c|c|c|}
\hline Responsibilities & Could Improve & Acceptable & Excellent & Not Observed* \\
\hline Access control & 1 & 9 & 2 & 0 \\
\hline Personnel vetting & 3 & 8 & 1 & 0 \\
\hline Packages searching & 0 & 5 & 7 & 0 \\
\hline Equipment kitting & 5 & 7 & 0 & 0 \\
\hline Guards -Public interaction & 6 & 3 & 3 & 0 \\
\hline Appears knowledgeable & 5 & 6 & 1 & 0 \\
\hline
\end{tabular}

Appendix 3 - A Regression Analysis to Determine the Contribution of the Effects of Commercial Security Services on National Security

\begin{tabular}{|c|c|c|c|c|c|}
\hline Model & $\mathrm{R}$ & $\mathrm{R}$ Square & Adjusted R Square & Std. Error of the Estimate & Durbin-Watson \\
\hline 1 & $.481 \mathrm{a}$ & .231 & .223 & .30771 & 1.042 \\
\hline $\begin{array}{l}\text { a. Predictors: (Constant), Intelligence of criminal activities through surveillance, Creating a culture of security and } \\
\text { crime awareness, Detection of criminal and harmful activities by the electronic devices, Intervening in stopping } \\
\text { crime and harm }\end{array}$ \\
b. Dependent Variable: National Security \\
\hline
\end{tabular}


ANOVA $^{\mathrm{a}}$

\begin{tabular}{|c|c|c|c|c|c|c|}
\hline \multicolumn{2}{|c|}{ Model } & Sum of Squares & df & Mean Square & F & Sig. \\
\hline \multirow{4}{*}{1} & Regression & 52.749 & 5 & 10.550 & 111.419 & $.000 \mathrm{~b}$ \\
\cline { 2 - 7 } & Residual & 34.844 & 368 & .095 & & \\
\cline { 2 - 7 } & Total & 87.594 & 373 & & & \\
\hline
\end{tabular}

a. Dependent Variable: National Security

b. Predictors: (Constant), Creating a culture of security and crime awareness, Visible presence that discourages criminal activities, Intervening in stopping crime, Intelligence of criminal activities through surveillance, Detection of criminal activities by the electronic devices

Appendix 4 - Scatterplots Between IVs and the DV. Effects of Commercial Security Services on National Security

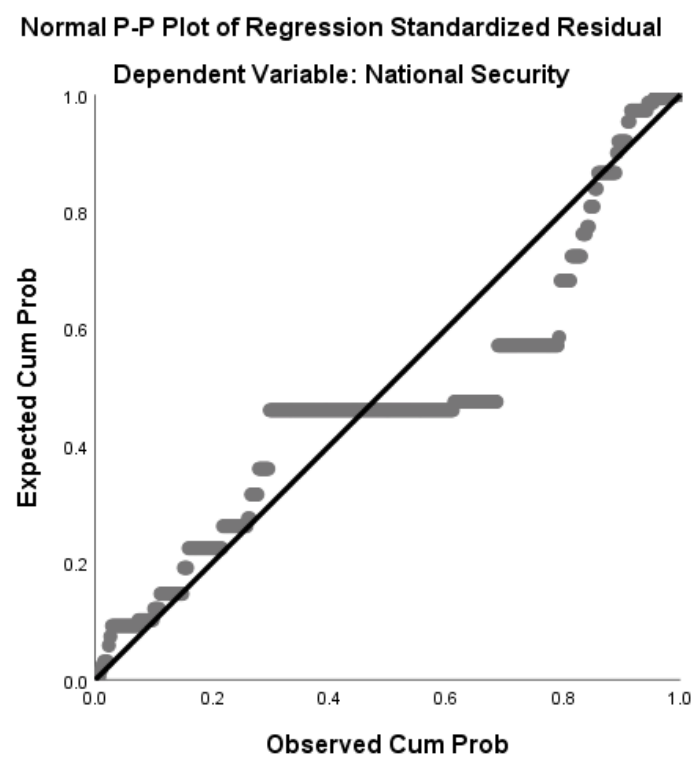

Appendix 5 - Plot of standardized residuals vs standardized predicted values. Effects of Commercial Security Services on National Security

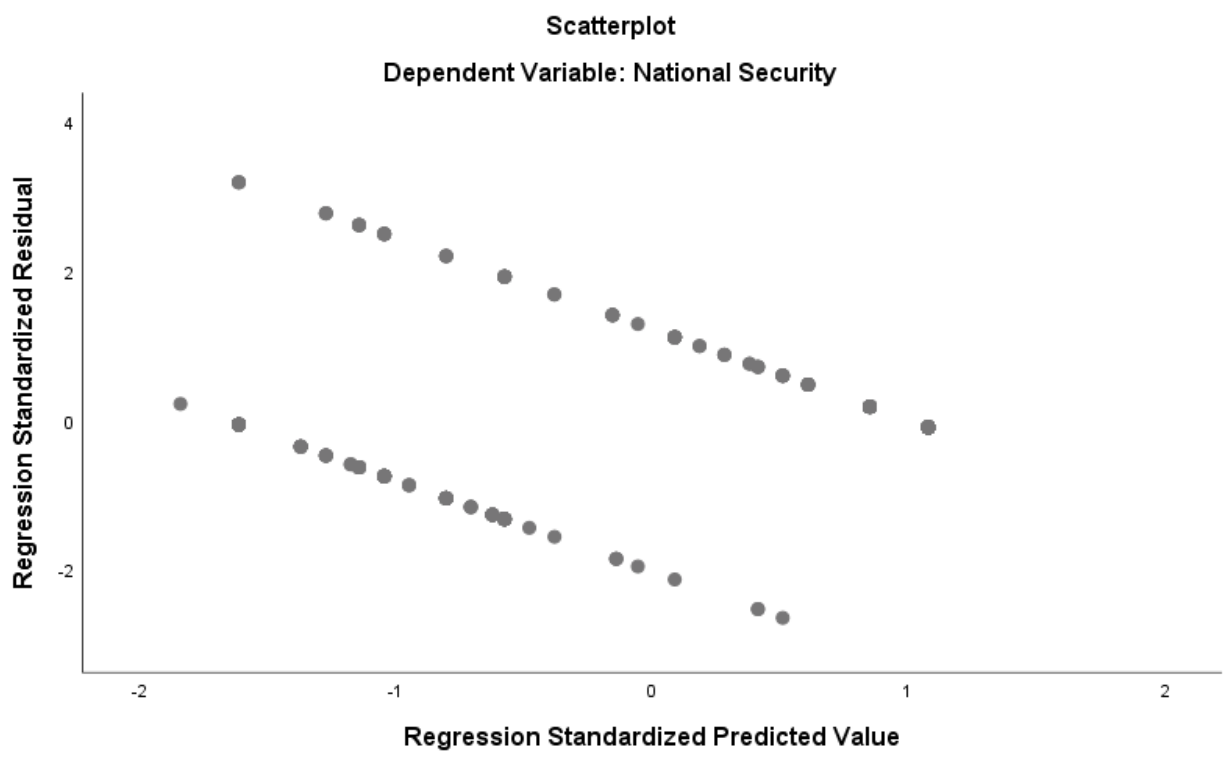


Appendix 6 - Multiple Regression Analysis Assumption Results

6.1. Assumption 1. The relationship between the IVs and the DV was linear. Scatterplots showed that this assumption had been met (Appendix III and Appendix IV).

6.2. Assumption 2. There was no multicollinearity in the data. Analysis of collinearity statistics shows this assumption has been met, as VIF score was well below 10, and tolerance score above 0.2. (Table 1)

6.3. Assumption 3. The values of the residuals are independent. The Durbin-Watson statistic showed that this assumption had been met, as the obtained value was 1.042 (Appendix III). For assumption \#3 to be met, this value has to be close to 2 . Values below 1 and above 3 are cause for concern and may render an analysis invalid.

6.4. Assumption 4. The variance of the residuals is constant. The plot of standardized residuals vs standardized predicted values showed no obvious signs of funneling, suggesting the assumption of homoscedasticity has been met (Appendix X).

6.5. Assumption 5. The values of the residuals are normally distributed. The Scatterplots for the model suggested that the assumption of normality of the residuals may have been violated. However, as only extreme deviations from normality are likely to have a significant impact on the findings, the results are probably still valid (Appendix IV).

6.6. Assumption 6. No influential cases are biasing the study model. Cook's Distance values were all under 1 , suggesting individual cases were not unduly influencing the model. 